\title{
"De Olho no Velho Chico": uma proposta de jogo didático para a alfabetização científica
}

\author{
"De Olho no Velho Chico": a proposal of didactic game for scientific literacy \\ "De Olho no Velho Chico": propuesta de juego dáctico para la alfabetización científica
}

Recebido: 16/09/2021 | Revisado: 22/09/2021 | Aceito: 25/09/2021 | Publicado: 27/09/2021

Erivânia Avelino Vicente Santos

ORCID: https://orcid.org/0000-0003-2883-0201 Instituto Federal de Educação, Ciência e Tecnologia de Alagoas, Brasil

E-mail: erivania.avsantos@gmail.com

Adalberon Moreira de Lima Filho

ORCID: https://orcid.org/0000-0003-0277-1047 Instituto Federal de Educação, Ciência e Tecnologia de Alagoas, Brasil E-mail: adalberon.filho@ifal.edu.br Jackson Moreira de Souza

ORCID: https://orcid.org/0000-0001-7148-1241 Instituto Federal de Educação, Ciência e Tecnologia de Alagoas, Brasil E-mail: jacksonmoreiradesouza@gmail.com

\begin{abstract}
Resumo
A escola é o local onde o aluno dará continuidade ao seu processo de formação enquanto indivíduo, sendo capaz de construir seus próprios valores e conceitos e, a alfabetização científica, nesse sentido, assume importância possibilitando que os alunos desenvolvam habilidades, além de um pensamento crítico e reflexivo. Nesse âmbito, o presente trabalho, utiliza de uma abordagem qualitativa de caráter descritivo para minuciar a proposta de um jogo didático denominado "De Olho no Velho Chico", tendo como objetivo desenvolver a alfabetização científica de alunos do Ensino Fundamental - Anos Finais por meio do conteúdo programático, Classe dos Vertebrados - Peixes, a partir da relação " homem x meio ambiente”, tendo como enfoque chamar a atenção para a situação atual do Rio São Francisco, e mais precisamente, a região do Baixo São Francisco. O jogo facilita o contato com a realidade, sendo capaz de associar o uso da ciência ao cotidiano. É importante ressaltar que o jogo ainda se encontra em fase de testes para verificar a sua viabilidade como um recurso didático capaz de dar início ao processo de alfabetização científica de alunos do ensino fundamental - anos finais.
\end{abstract}

Palavras-chave: Alfabetização científica; Rio São Francisco; Jogo didático.

\begin{abstract}
The school is the place where the student continues his formal education as individual, being capable of building his own values and concepts, and the scientific literacy in this matter takes on importance enabling the students the development of skills in addition to a critical e reflexive thinking. In this scope, this paper uses a qualitative approach of descriptive feature to detail the proposal of a didactic game called "De Olho no Velho Chico", having as goal the development of scientific literacy in high school students - final years, throughout program content, vertebrate class fish, starting from the relation "man x environment", focusing in drawing attention to the current situation of the San Francisco river, more precisely, the area of the low San Francisco. The game facilitates the contact with the reality, being capable of associating the use of science with the daily life. It is important to point out that the game is still being tested to verify its feasibility as didactic resource capable of starting the process of scientific literacy of high school students - final years.
\end{abstract}

Keywords: Scientific literacy; San Francisco River; Didactic game.

\section{Resumen}

La escuela es el lugar donde el alumno continuará su proceso de formación como individuo, pudiendo construir sus propios valores y conceptos y, la alfabetización científica, en este sentido, cobra importancia permitiendo al alumno desarrollar habilidades, además del pensamiento crítico. y reflexivo. En este contexto, el presente trabajo utiliza un enfoque cualitativo de carácter descriptivo para detallar la propuesta de un juego didáctico denominado "De Olho no Velho Chico", con el objetivo de desarrollar la alfabetización científica de los estudiantes de Educación Primaria Últimos Años a través del contenido programático, Clase de Vertebrados - Piscis, basado en la relación "hombre $\mathrm{x}$ ambiente”, enfocándose en llamar la atención sobre la situación actual del río São Francisco, y más precisamente, la región del Bajo São Francisco. El juego facilita el contacto con la realidad, pudiendo asociar el uso de la ciencia con la vida cotidiana. Es importante señalar que el juego aún se encuentra en fase de prueba para verificar su viabilidad 
como recurso didáctico capaz de iniciar el proceso de alfabetización científica de los alumnos de primaria - últimos cursos.

Palabras clave: Alfabetización científica; Río São Francisco; Juego didáctico.

\section{Introdução}

Durante o componente curricular Estágio Supervisionado I, que propõe ao discente a observação direta de todo o âmbito escolar, desde o gerenciamento até o decorrer das aulas, foi possível observar nas aulas de ciências do ensino fundamental - anos finais, a carência e a escassez de recursos didáticos, uso do livro como principal e único recurso, além da pouca informação de cunho ambiental e a forte cultura da memorização como processo de ensino e aprendizagem.

O professor precisa refletir/repensar constantemente sua prática pedagógica para a adoção de uma postura interdisciplinar, cuja mediação utilize abordagens contextualizadas que possam ir ao encontro da realidade cotidiana do aluno (Oliveira et al., 2018, p. 92). Nesse sentido surgiu, então, uma inquietação a respeito de como seria possível ofertar um recurso de produção viável que interligasse o conteúdo didático com a realidade cotidiana dos discentes, instigando o desenvolvimento de um pensamento crítico, no qual o aluno fosse capaz de conectar os conteúdos programáticos com o seu dia a dia, tornandose agente do seu processo de aprendizagem.

A escola campo de observação durante o componente curricular Estágio Supervisionado I fica localizada no município de Penedo, ao sul do estado de Alagoas, às margens do Rio São Francisco, na divisa com o estado de Sergipe. Por ser uma cidade ribeirinha, possui parte de sua economia voltada à pesca artesanal. E esse foi o ponto-chave para que a proposta fosse desenvolvida: elaborar um jogo didático envolvendo algo que está presente de forma muito marcante para esses alunos: o Rio São Francisco.

A escola é o local onde o aluno dará continuidade ao seu processo de formação enquanto indivíduo, e, de acordo com Paulo Freire, a educação deve contribuir para a construção de um ser humano autônomo, ao contrário de práticas repetitivas" que domesticam o sujeito para a manutenção e repetição de valores pré-estabelecidos (Freire, 2016), o qual será capaz de construir seus próprios valores e conceitos ao longo de sua construção pessoal.

E, nesse sentido, a Base Nacional Comum Curricular (BNCC), homologada em 2018, propõe que o ensino das Ciências da Natureza, o qual envolve os componentes biologia, química e física, inicie o processo de Letramento Científico e/ou Alfabetização Científica nos alunos. A Alfabetização Científica considera que o ensino não deve se limitar a memorização de termos e conceitos científicos, sendo de fundamental importância que os discentes compreendam os fatores envolvidos na produção do conhecimento científico e a relação existente entre tal conhecimento, a sociedade, a tecnologia, e o meio ambiente (Auler \& Delizocov, 2001; Sasseron \& Carvalho, 2008).

No campo das ciências, para que a alfabetização científica aconteça, é importante que haja inovações no currículo das escolas, a começar pelo uso de materiais que conectam o conteúdo didático ao contexto social dos alunos, e, nessa perspectiva, destaco a utilização de jogos didáticos. Godoi (2010, p. 22) enfatiza que

Quando vinculado aos conteúdos disciplinares, os jogos podem ser considerados educativos se desenvolverem habilidades cognitivas importantes para o processo de aprendizagem, tais como resolução de problemas, percepção, criatividade, raciocínio rápido, dentre outras. Quando um jogo é elaborado com o objetivo de atingir os conteúdos específicos para serem utilizados no meio escolar, este é denominado de jogo didático (Godoi, 2010 p. 22).

Por meio dos jogos, os alunos "adquirem diversas experiências, interagem com outras pessoas, organizam seu pensamento, tomam decisões, desenvolvem o pensamento abstrato e criam maneiras diversificadas de jogar, brincar e produzir conhecimentos" (Vieira \& Oliveira, 2010, p. 2). Os jogos podem servir como estratégias para produção de vínculos entre os conteúdos programáticos e as questões socioculturais demandadas por um ensino transdisciplinar (Meirelles, Sant'ana \& 
Lopes, 2015), favorecem também a formação cidadã dos alunos, pois podem auxiliar no "entendimento de regras e valores que decorrem dos jogos, bem como o respeito ao próximo e desenvolvimento de habilidades relacionadas ao raciocínio lógico, motricidade, senso de responsabilidade, estímulo à cooperação, dentre outros" (Aliane et al., 2018, pp. 106-107).

Além disso, podem contribuir para superar as limitações do ensino conteudista, permitindo o desenvolvimento da habilidade de resolver problemas, favorecer a compreensão de conceitos e enriquecer as experiências pessoais entre professor e aluno (Aliane et al., 2018, pp. 106-107). Seguindo esse contexto, o presente trabalho traz uma proposta de jogo didático denominado "De Olho no Velho Chico", o qual foi elaborado a partir de adaptações dos tradicionais jogos de tabuleiro. O jogo foi delineado conforme os parâmetros da Base Nacional Comum Curricular (BNCC), a qual expõe que

A área de Ciências da Natureza, no Ensino Fundamental, propõe aos estudantes investigar características, fenômenos e processos relativos ao mundo natural e tecnológico, explorar e compreender alguns de seus conceitos fundamentais e suas estruturas explicativas, além de valorizar e promover os cuidados pessoais e com o outro, o compromisso com a sustentabilidade e o exercício da cidadania (Brasil, 2018, p. 471).

Por fim, a concepção desse trabalho tem por objetivo a elaboração de um jogo didático capaz desenvolver a alfabetização científica de alunos do Ensino Fundamental - Anos Finais por meio do conteúdo programático, Classe dos Vertebrados - Peixes, a partir da relação " homem x meio ambiente”, tendo como enfoque chamar a atenção para a situação atual do Rio São Francisco, e mais precisamente, a região do Baixo São Francisco com seus problemas envolvendo temas como impactos ambientais causados pela pouca preservação, conservação, o não uso sustentável e diminuição da ictiofauna.

\section{Metodologia}

O presente trabalho utilizou-se de uma abordagem qualitativa de caráter descritivo (Barbato, 2008) para minuciar a elaboração de um jogo didático que busca contribuir para o processo de alfabetização científica de alunos do ensino fundamental - anos finais.

Inicialmente foi delimitada a temática principal do jogo com base no currículo da disciplina de ciências: o estudo da Zoologia com foco na Classe dos Vertebrados - Peixes. Posteriormente determinaram-se os temas secundários inerentes ao conteúdo. Foi realizado um levantamento bibliográfico sobre elaboração e uso de jogos como recurso didático na alfabetização científica, bem como problemas socioambientais envolvendo o Baixo São Francisco.

No âmbito da Classe dos Vertebrados - Peixes, optou-se por incluir algumas espécies nativas e exóticas presentes na região do Baixo São Francisco e também algumas em extinção, de modo a aproximar os alunos da sua realidade, já que a localidade foco dessa proposta, o município de Penedo, é banhado pelo Rio São Francisco (Baixo São Francisco), fazendo divisa do estado de Alagoas com o estado de Sergipe.

Os temas secundários foram escolhidos de modo a relacionarem-se diretamente com questões socioambientais típicas dessa mesma região, tais como: pesca com métodos não permitidos, desmatamento da vegetação ciliar, assoreamento, poluição de efluentes da cidade e agrotóxicos, derramamento de esgotos e lixo jogados na calha do rio.

A ideia inicial era que o jogo didático fosse confeccionado para uso em sala de aula, para dinamizar as aulas de ciências. Mas, devido ao cenário atual em que a educação se encontra, em decorrência da pandemia do Covid-19, foi necessário adaptar essa ideia para atender ao novo contexto de ensino. No caso do ensino remoto, o jogo impresso pode ser ofertado aos alunos de forma individual para que usufruam em casa, na companhia dos familiares, proporcionando além de uma aprendizagem significativa, a aproximação dos familiares em um momento de lazer e muito aprendizado. 
O mesmo também pode ser utilizado de forma online, pois oferece um design gráfico virtual capaz de ser administrado pelo professor em aulas online com auxílio das plataformas virtuais mais utilizadas na região, como, por exemplo 'Google Meet' e 'Google Drawing'.

Diante desse novo cenário, vários protótipos foram produzidos (Figura 1) até chegar a uma versão final a qual atendesse completamente a ideia, o objetivo e o contexto educacional.

Figura 1. Croqui elaborado com a ideia de formatação do jogo didático.

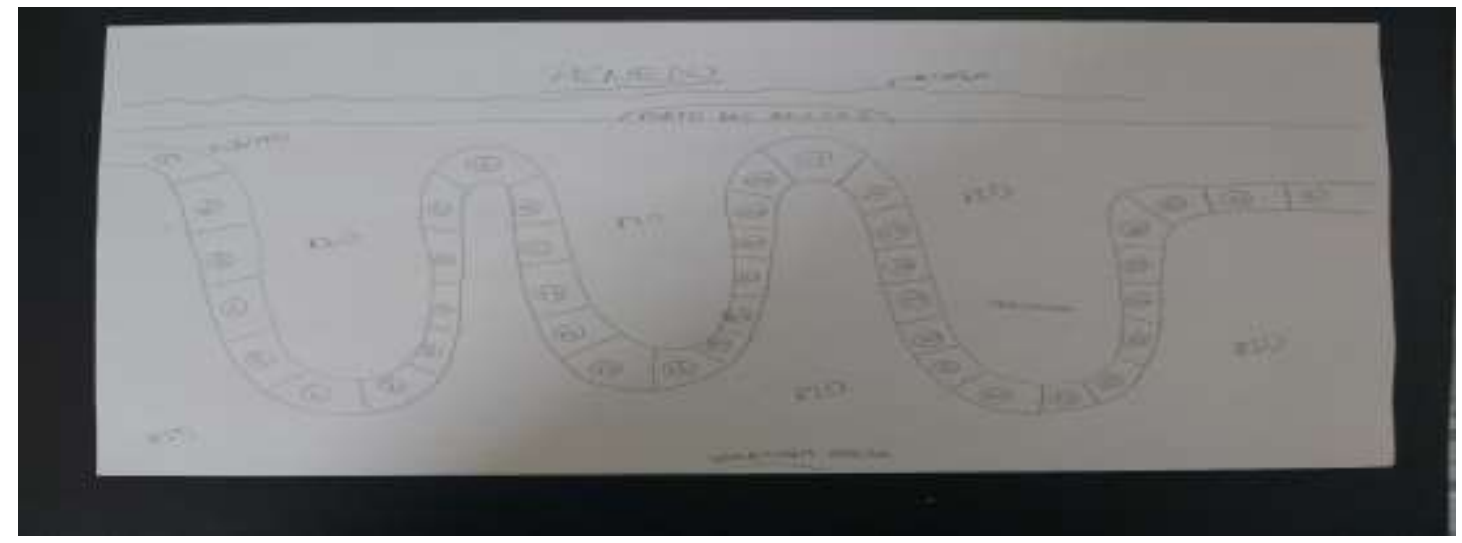

Fonte: Acervo pessoal.

Optou-se por desenvolver um jogo no qual o tabuleiro possuísse um design que simula o centro da cidade de Penedo - AL, banhada pelo rio São Francisco com detalhes característicos que dimensionam o jogador a um cenário próximo de sua realidade (Figura 2).

Figura 2. Protótipo inicial do jogo didático simulando a orla da cidade ribeirinha de Penedo-AL.

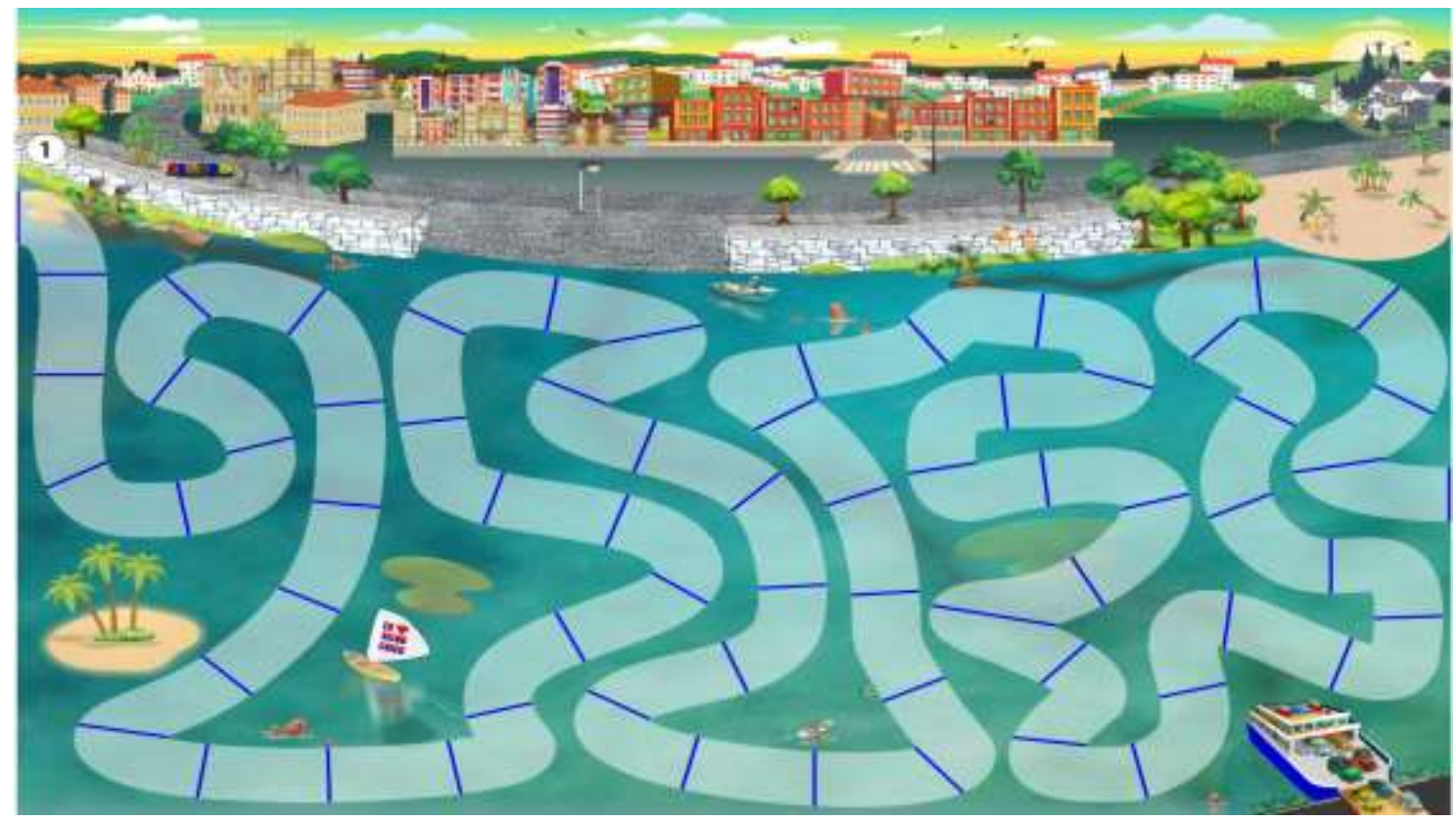

Fonte: Acervo pessoal.

Todo o design gráfico foi produzido utilizando - se o programa de edição gráfica Corel Draw versão 2012. O tabuleiro teve seu cenário inspirado na orla ribeirinha da cidade de Penedo-AL, inserindo-se detalhes que caracterizam a 
região: alguns pontos turísticos históricos como o Museu do "Paço Imperial" e a Igreja Nossa Senhora das Correntes; além do Porto das Balsas, onde lanchas e carros fazem a travessia Alagoas/Sergipe (Penedo/AL - Neópolis/SE); a nova Prainha de água doce, muito frequentada pelos munícipes e turistas e ao fundo tem-se prédios que simbolizam os sobrados que, atualmente, servem de habitações comerciais.

\section{Resultados e Discussão}

O jogo foi intitulado "De Olho no Velho Chico" e será apresentado ao longo desta seção em três subtópicos: Descrição do Jogo, Componentes do Jogo, Instruções do Jogo e Contribuição Pedagógica.

\subsection{Descrição do Jogo}

"De Olho no Velho Chico" é um jogo educativo, estruturado por recursos lúdicos visuais, no qual os alunos se movem ao longo de um tabuleiro, conforme o lançamento de dados e ações pré-definidas no jogo. A quantidade de jogadores pode variar de 1 a 5 participantes. Pode ser facilmente utilizado de forma individual e, nesse caso, não há vencedores, apenas obtenção de conhecimento; ou com dois ou mais participantes, assim, um deverá ser escolhido para ser o mediador.

Em aulas presenciais, o professor atua como mediador direcionando as regras e as tarefas a serem executadas em cada etapa do jogo. Estima-se que para a sua aplicação seja necessária apenas uma hora/aula (50 minutos) no âmbito da educação presencial. Foi idealizado para ser utilizado com alunos do ensino fundamental, no entanto possui faixa etária de classificação livre.

Para utilizar o jogo, o professor deverá apenas utilizar o kit físico (impresso) do jogo. O kit físico é composto por: 01 Tabuleiro com 64 casas; 1 Manual de Instruções; 2 dados e 4 pinos personagens (Curimatã-pacu, Pacamã, Pirá, Tucunaré que devem ser escolhidos por cada jogador).

Cada pino representa espécies de peixes endêmicas do Rio São Francisco, como é o caso do Pacamã (Lophiosilurus alexandrii) (Shibata, 2003) e da Curimatã-pacu (Prochilodus argenteus) (Sato et al. 1996a; Sato \& Godinho, 2003), espécie endêmica em extinção, como o Pirá (Conorhynchos conirostris) (PAN, 2020) e uma espécie exótica, como o Tucunaréamarelo (Cichla monoculus) (Santos et al., 1994). Os pinos são diferenciados por cores, a serem escolhidas a critérios dos jogadores. Portanto, o jogo é composto por: um tabuleiro (Figura 3); Dois dados e 4 pinos (Figura 4), além de um Manual de Instruções e Instruções do Jogo e Manual de Instruções (trilha) (material complementar do "De Olho no Velho Chico") 
Figura 3. Design gráfico do tabuleiro do jogo "De Olho no Velho".

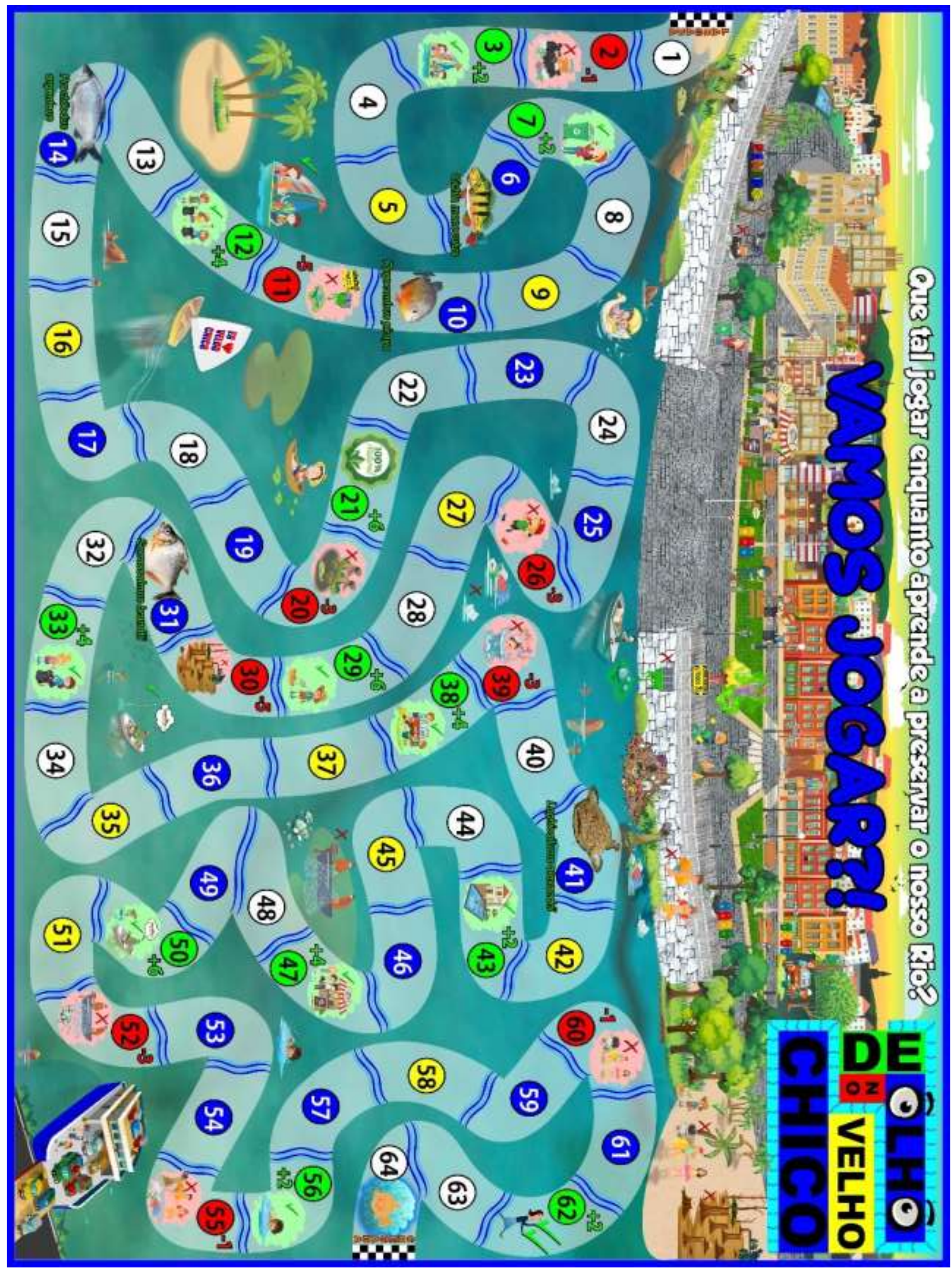

Fonte: Acervo Pessoal. 


\section{Figura 4. Dados e pinos do jogo "De Olho no Velho Chico".}
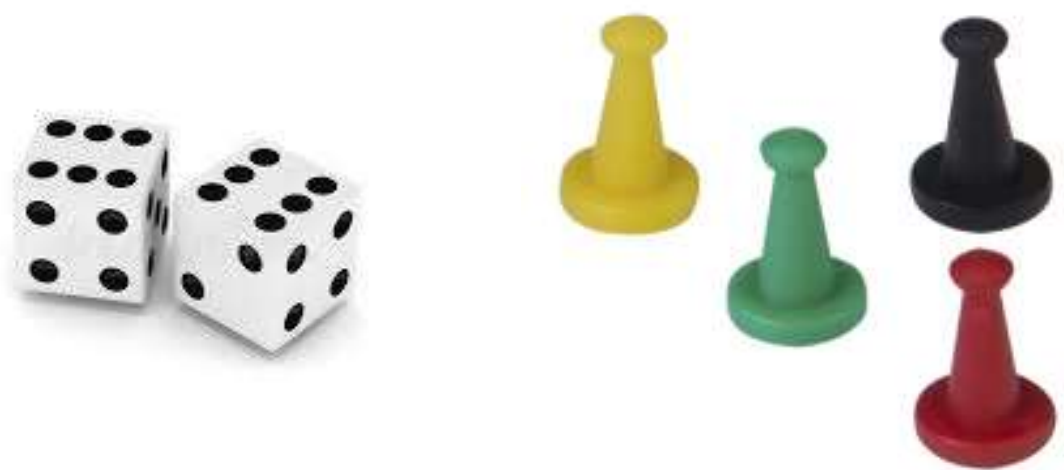

Fonte: Google. (Imagem meramente ilustrativa).

\subsection{Contribuição Pedagógica}

"De Olho no Velho Chico" apresenta graus de dificuldades variadas e a cada sequência de jogadas os jogadores evolem no ganho de conhecimento de cunho educacional e ambiental. O jogo possui como função pedagógica complementar o estudo da zoologia dando início ao processo de alfabetização científica, possibilitando a ampliação do conhecimento sobre o conteúdo aproximando-o da vivência e do cotidiano do aluno.

Todas as situações colocadas no decorrer do jogo fazem parte das experiências cotidianas dos alunos e com isso, o jogo facilita o contato com essa realidade, sendo capaz de associar o uso da ciência ao seu dia-a-dia. É importante ressaltar que o jogo ainda se encontra em fase de testes para verificar a sua viabilidade como um recurso didático capaz de dar início ao processo de alfabetização científica de alunos do ensino fundamental - anos finais a partir da interligação entre sua realidade cotidiana e o conteúdo programático do componente ciências - Zoologia - Classe de Vertebrados - Peixes.

Diversas instituições de ensino e docentes ainda insistem em manter modelos de aulas prontas e roteiros previamente definidos para sequenciar suas aulas. Todavia, aspirando o aperfeiçoamento do processo de ensino e aprendizagem, o professor pode enriquecer esses materiais prontos com o uso de metodologias que tenham como foco o aluno, na colaboração e na personalização, como pesquisas, aulas invertidas, integração entre sala de aula e atividades online, projetos integradores e jogos (Souza \& Morales, 2015).

A utilização dos jogos em uma abordagem educacional traz como uma de suas principais vantagens tornar os estudantes participantes ativos ao invés de meramente observadores passivos, permitindo a tomada de decisões, a resolução de problemas e a reação aos resultados das suas próprias decisões (Franklin et al., 2003). Esses pontos são evidenciados no decorrer do jogo, uma vez que durante o percurso os jogadores são postos a resolução de questões que instigam o raciocínio para tomada de decisões e resolução de problemas ali destacados, os quais fazem ligação direta com a atuação do cidadão perante a sociedade.

No âmbito da Base Nacional Comum Curricular, o componente curricular de ciências está dividido em três unidades temáticas que se repetem durante todo o ensino fundamental. Dentre elas, tem-se a unidade temática Vida e Evolução:

A unidade temática Vida e evolução propõe o estudo de questões relacionadas aos seres vivos (incluindo os seres humanos), suas características e necessidades, e a vida como fenômeno natural e social, os elementos essenciais à sua manutenção e à compreensão dos processos evolutivos que geram a diversidade de formas de vida no planeta. Estudam-se características dos ecossistemas destacando-se as interações dos seres vivos com outros seres vivos e com 
os fatores não vivos do ambiente, com destaque para as interações que os seres humanos estabelecem entre si e com os demais seres vivos e elementos não vivos do ambiente. Abordam-se, ainda, a importância da preservação da biodiversidade e como ela se distribui nos principais ecossistemas brasileiros (Brasil, 2018, p.326)

Ainda segundo a BNCC,

Nos anos finais, a partir do reconhecimento das relações que ocorrem na natureza, evidencia-se a participação do ser humano nas cadeias alimentares e como elemento modificador do ambiente, seja evidenciando maneiras mais eficientes de usar os recursos naturais sem desperdícios, seja discutindo as implicações do consumo excessivo e descarte inadequado dos resíduos. Contempla-se, também, o incentivo à proposição e adoção de alternativas individuais e coletivas, ancoradas na aplicação do conhecimento científico, que concorram para a sustentabilidade socioambiental. Assim, busca-se promover e incentivar uma convivência em maior sintonia com o ambiente, por meio do uso inteligente e responsável dos recursos naturais, para que estes se recomponham no presente e se mantenham no futuro (Brasil, 2018, p. 327).

Assim, jogo didático "De Olho no Velho Chico", tendo como foco o Rio São Francisco é uma proposta lúdica de recurso didático que pode ser inserido durante as aulas de ciências, pois possui embasamento nos Parâmetros Curriculares Nacionais e na Base Nacional Comum Curricular, uma vez que, além de atuar como uma ferramenta de ensino, integrando-a a temática Zoologia - Classe Vertebrados - Peixes, pode ser utilizada como ferramenta iniciação a alfabetização científica.

Por apresentar termos, conhecimentos e conceitos científicos fundamentais, além de auxiliar a compreensão de fatores éticos e a relação existente entre ciência, tecnologia, sociedade e ambiente, pode-se inferir que o jogo se enquadra nos eixos estruturantes definidos por Sasseron e Carvalho (2008),

O primeiro eixo configura-se na "compreensão básica de termos, conhecimentos e conceitos científicos fundamentais"; o segundo refere-se à "compreensão da natureza das ciências e dos fatores éticos e políticos que circundam sua prática"; e o terceiro "compreende o entendimento das relações existentes entre ciência, tecnologia, sociedade e ambiente”. (Sasseron \& Carvalho, 2008, p. 3).

Conforme a distribuição dos indicadores propostos por Sasseron \& Carvalho (2008), o primeiro grupo agrupa habilidades de seriação, organização e classificação de informações, o segundo grupo, compreende habilidades de raciocínio lógico e proporcional; e o terceiro, envolve os indicadores ligados ao levantamento de hipótese, teste de hipótese, justificativa, previsão e explicação.

No primeiro grupo, o professor poderá trabalhar com os alunos habilidades de seriação, à medida em que responderão questionamentos expostos no jogo, com base em suas experiências cotidianas. A exemplo das perguntas das casas 4 (qual a importância de descartar o lixo corretamente (na lixeira)?), e 40 (você conhece alguma ação para evitar o desperdício de água?). Essas perguntas (e outras dispostas no decorrer do jogo) instigarão os alunos a refletirem sobre suas experiências passadas, sobre seus conhecimentos prévios a respeito dos temas; poderão trabalhar ainda, habilidades de organização e classificação de informações, estruturando as experiências prévias dos alunos com as novas informações elencadas no jogo. Esse indicador é bastante pontuado através da complementação dos temas no decorrer do percurso da trilha.

No segundo grupo, o professor poderá trabalhar a estruturação do pensamento dos alunos, articulando e alinhando as ideias e explanações sobre o meio ambiente e a sociedade. E, no terceiro grupo, desenvolverá a construção do conhecimento científico (levantamento de hipóteses, justificativa e explicação), pois a partir da exposição dos conhecimentos prévios, correlacionados a novas informações, o aluno será capaz de formular suas próprias conclusões, criando assim, novos conhecimentos, novas ideias.

\section{Conclusão}

"De Olho no Velho Chico" é um jogo de tabuleiro didático proposto como um recurso de auxílio capaz de complementar e incrementar as aulas de Zoologia - Classe de Vertebrados - Peixes, facilitando a aprendizagem significativa a 
partir da conexão entre o conteúdo didático e a realidade. Foi produzido com a percepção de trabalhar peixes em seus termos científicos (nome científico da espécie) e soluções de problemas do cotidiano, de modo a dar início ao processo de alfabetização científica dos alunos. Possui como vantagens o baixo custo de produção para o professor, facilidade de aplicação e faixa etária livre, apesar de ter sido confeccionado com foco em alunos do ensino fundamental. A proposta de se desenvolver a alfabetização científica por meio de um jogo didático é uma alternativa de aproximar o saber científico do cotidiano e da vida dos alunos, sem desprestigiar as aprendizagens tão necessárias e fundamentais em Ciências, composta no currículo.

Alicerçado nas propostas da alfabetização científica, pode-se pensar em superar uma compreensão baseada em leitura, memorização e repetição, acreditando que o entendimento e a aprendizagem por meio de processos envolvidos na alfabetização científica podem contribuir também para a construção de saberes.

O jogo possui embasamento nos Parâmetros Nacionais Curriculares, na Base Nacional Comum Curricular e nos Eixos Estruturantes e indicadores de Alfabetização Científica, no entanto, estudos futuros com foco na sua aplicabilidade em sala de aula, visando analisar minuciosamente quais habilidades no campo da alfabetização científica esse recurso didático é capaz de atingir, necessitam ser realizados, a fim de comprovar a sua viabilidade educativa.

\section{Referências}

Aliane, C. S. M., Reis, R. C., César, E. T. \& Lopes, J. G. S. (2018). Lona Periódica: Promovendo reflexões em um processo de formação continuada com professores de Química. REDEQUIM - Revista Debates em Ensino de Química. 4(1), 102-129.

Almeida, J. M., Lima, R. M., Silva, M. S. L., Véras, M. A. S. \& Cavalcanti, M. L. F. (2015). Ensino e aprendizagem de ciências biológicas, com a utilização de jogos didáticos: relato de experiência. In Congresso Nacional da Educação II. Campina Grande-PB. Anais...

Auler, D. \& Delizoicov, D. (2001). Alfabetização científico-tecnológica para quê? Ensaio - Pesquisa em Educação em Ciências. 3(1).

Barbato, S. (2008). Metodologia de pesquisa qualitativa. Editora UNB.

Barbosa, J. M. \& Soares, E. C. (2009). Perfil da ictiofauna da bacia do São Francisco: Estudo preliminar. Revista Brasileira de Engenharia de Pesca 4(1), 155172.

Barbosa, J. M., Soares, E. C., Cintra, I. H. A., Hermann, M., Araújo, A. R. R. (2017). Perfil da ictiofauna da bacia do Rio São Francisco. Acta fish. Aquat. Res. $5(1), 70-90$

Brasil. (2018). Ministério da Educação. Base Nacional Comum Curricular. Mec.

Cachapuz, A., Gil-Perez, D. \& Carvalho, A. M. P. (2005). Necessária renovação do ensino das ciências. Cortez.

Cunha, M. B. (2012). Jogos no ensino de química: Considerações teóricas para sua utilização em sala de aula. Química Nova na Escola. 34(2), 92-98.

Fialho, N. N. (2008). Os jogos pedagógicos como ferramentas de ensino. In Congresso Nacional de Educação, VIII Educere. Anais...

Filho, R. S., Oliveira, K. M. G., Tureck L. V., Alle, L. F. \& Leme, D. M. (2020). Ciência na escola: Elaboração, aplicação e avaliação de um jogo na temática de ecotoxicologia como ferramenta de educação científica. Revista Eletrônica Ludus Scientiae - (RELUS) 4(1), 114-134.

Franklin, S., Peat, M. \& Lewis, A. (2003). Non-tradicional interventions to stimulate discussion: the use of games and puzzles. J. Biological educ. 37(2), 7984.

Freire, P. (2016). Pedagogia do Oprimido. (60a ed.), paz e terra.

Freire, P. (1980). Educação como prática da liberdade. Paz e Terra.

Gardner, H. (1993). Frames of mind: the theory of multiple intelligences. (10a ed.), Basic books.

Godoi, T. A. F., Oliveira, H. P.M. \& Codognoto, L. (2010). Tabela periódica - um super trunfo para alunos do ensino fundamental e médio. Revista Química Nova na Escola. 32(1).

Guimarães, M. (2010). A dimensão ambiental na educação. (10a ed.), Papirus.

Krasilchik, M. E. \& Marandino, M. (2007). Ensino de ciências e cidadania. São Paulo, Moderna.

Leão, M. A. (2015). O uso de jogos como mediadores da alfabetização/letramento em sala de apoio das séries iniciais. Estudos linguísticos. $44(2)$, 647 656.

Medeiros, M. D. F. (2016). Indicadores de alfabetização científica em uma aula experimental investigativa sobre fotossíntese e respiração celular para o sétimo ano do ensino fundamental. Dissertação (mestrado) - Faculdade de Educação, Instituto de Biociências, Instituto de Física, Instituto de Química da Universidade de São Paulo. 101. 
Medeiros P.R.P., Dos Santos M., Cavalcante G.H., Souza W.F.L. \& Silva W.F. (2014). Características ambientais do Baixo São Francisco (AL/SE): Efeitos de barragens no transporte de materiais na interface continente-oceano. Geochimica brasiliensis. 28(1), 65-78.

Medeiros, P. R. P., Segundo, G. H. C. \& Magalhães, E.M. M. (2015). Comportamento da turbidez e material em suspensão, em um rio com vazão regularizada por sistema de barragens em cascata: Rio São Francisco (NE, BRASIL). Geochimica brasiliensis. 29(1), 35-44.

Meirelles, M. A., Sant'ana, A. C. \& Lopes, J. G. S. (2015). Uma abordagem interdisciplinar envolvendo bioquímica e termoquímica através de um jogo pedagógico. In: reflexões sobre formação de professores e ensino de química. Livr. Da física, 165-175.

Oliveira, A. L., Oliveira, J. C. P., Nasser, M. J. S. \& Cavalcante, M. P. (2018). O jogo educativo como recurso interdisciplinar no ensino de química. Quím. Nova Esc. 40(2), 89-96.

Pizarro, M. V. \& Junior, J. L. (2015) Indicadores de alfabetização científica: Uma revisão bibliográfica sobre as diferentes habilidades que podem ser promovidas no ensino de ciências nos anos iniciais. Investigações em Ensino de Ciências. 20(1), 208-238.

Sampaio, C. L. S., Paiva, A. C. P \& Soares, E. C. (2015). Peixes, pesca e pescadores do Baixo São Francisco, Nordeste do Brasil. In: A pesca artesanal no Baixo São Francisco, atores, recursos, conflitos. Org. Souza, E.M. \& Sá, M.F.P. 105-148.

Santana, E. M. \& Rezende, D. B. (2008). O uso de jogos no ensino e aprendizagem de química: Uma visão dos alunos do $9^{\circ}$ ano do ensino fundamental. XIV Encontro Nacional de Ensino de Química. UFPR.

Santos, G.B., P.M. Maia-Barbosa, F. Vieira \& C.M. López. (1994). Fish and zooplâncton communities structure in reservoirs of southestern brazil: et tects of the introduction of exotic predatory fish. 115-132.111: in: r. M. Pinto-Coelho, A. Giani \& E. Von Sperling (eds). Ecology and human impact on lakes and reservoirs in Minas Gerais with special reference to future development and management strategies. SEGRAC. 435.

Santos, A. B. Dos. \& Guimarães, C. R. P. (2010). A utilização de jogos como recurso didático no ensino de zoologia. Rev. Electrón. Investig. Educ.Cienc. $5(2)$.

Sasseron, L. H. \& Carvalho, A. M. P. (2008). Almejando a alfabetização científica no ensino fundamental: A proposição e a procura de indicadores do processo. Investigações em ensino de ciências. 13(3), 333-352.

Sato, Y., Cardoso, E. L., Godinho, A. L. \& Godinho, H. P. (1996). Hypophysation parameters of the fish prochilodus marggravvi obtained in routine hatchery station conditions. Revista Brasileira de Biologia. 56, 59-64.

Sato, Y. \& Godinho, H. P. (2003). Migratory fishes of the São Francisco River. In: Carolsfeld J, Harvey B, Ross C \& Baer A. Migratory fishes of south america: biology, fisheries and ecological status. Victoria, Canadian: IDRC, 195-232.

Shibata, O. A. (2003). Family Pseudopimelodidae. In: Reis, R. E.., Kullander, S. O., Ferraris, J. R., C. J. Check list of the freshwater fisher of south and Central America. EDIPUCRS, 401-405.

Silva, J. C. S. \& Bianco, G. (2020). Jogos didáticos: A formação educativa através de uma aprendizagem significativa e um currículo adaptado por projetos. Research, Society and Development. 9(9).

Silva, A. F., Aguiar Júnior, O. \& Belmiro, C. A. (2015). Imagens e desenhos infantis nos processos de construção de sentidos em uma sequência de ensino sobre o ciclo da água. Ensaio pesquisa em educação em ciências. 17(3), 607-632.

Silva, I. V., Fonsceca, L. M., Tavares, C. S., Tavares, C. S., Carmo, A. M. \& Sant'ana, A. C. (2019). Desenvolvimento de jogos didáticos auxiliares em práticas transdisciplinares e da alfabetização científica no ensino das ciências da natureza. Revista Insignare Scientia. 2(4).

Soares, E. C., Bruno, A. M. S., Dantas, J. M. \& Santos, R. B. (2011). Ictiofauna e pesca no entorno de Penedo, Baixo São Francisco, Alagoas. Biotemas (UFSC), 24, 61-67.

Soares, E. C et al. (2020). Análise da ictiofauna e dos seus aspectos fisiológicos na II expedição científica do Baixo São Francisco para ações de manejo. Relatório da II Expedição Científica do Baixo São Francisco, 28 - 56.

Soares, E. C., Silva, J. V., Navas, R., Silva, T. J. \& Costa, S. S. L. (2020). Relatório da II expedição do Baixo São Francisco. 560.

Soares, M. H. F. B. (2016). Jogos e atividades lúdicas no ensino de química: uma discussão teórica necessária para novos avanços. REDEQUIM - Revista Debates em Ensino de Química. 2(2).

Souza, P. \& Barros, M. (2012). Jogos interativos: uma possibilidade no ensino de ciências para a educação de jovens e adultos. III Encontro Nacional de Ensino de Ciências da Saúde e do Ambiente, 16

Torres, T. P. S. \& Andrade, D. C. (2015). Xadrezoo: uma proposta de jogo didático de zoologia para estudantes do ensino médio. In Congresso Nacional da Educação II. Campina Grande - PB. Anais...

Vieira, L. S. \& Oliveira, V. X. (2010). A importância dos jogos e brincadeiras para o processo de alfabetização e letramento. Anais do V EPCT - Encontro de Produção Científica e Tecnológica. Faculdade Estadual de Ciências e Letras de Campo Mourão/Núcleo de Pesquisa Multidisciplinar. Alessandra Augusta Pereira da Silva (org.). Campo Mourão: FECILCAM/NUPEM. 


\section{Material complementar do jogo "De Olho no Velho Chico"}

a) Instruções:

1) Os participantes deverão escolher o personagem com o qual desejam jogar: Pacamã, Pirá, Curimatã-pacu e Tucunaré e a cor para representar cada personagem.

2) Os participantes deverão posicionar os pinos escolhidos na casa "INÍCIO".

3) A escolha do jogador que fará a primeira jogada ficará a critério dos integrantes. Cada participante deverá lançar os dois dados uma única vez e a soma dos pontos será o total de casas que este deverá avançar.

4) As casas na cor verde representam atitudes positivas.

5) As casas na cor vermelha representam atitudes negativas.

6) As casas na cor azul são compostas por conhecimentos específicos sobre peixes, poluição e preservação do rio.

7) As casas na cor branca representam "Sorte ou Azar". Nessas casas estão dispostas perguntas sobre conhecimentos específicos em peixes e meio ambiente. Após o mediador realizar a leitura da pergunta, o participante dispõe de 10 segundos para responder. Caso erre a resposta ou não consiga responder em tempo hábil, deverá permanecer na mesma casa. Caso acerte a resposta, avança 1 casa.

8) Ganha o jogo o participante que chegar primeiro à casa "CHEGADA"

\section{b) Trilha de regras:}

CASA 1) INÍCIO

CASA 2) Apesar de ter lixeira nas ruas, jogaram o lixo no chão e com a ajuda do vento e da chuva, esse lixo foi levado para as águas do rio. Estava nadando com meus amigos e não vi, fiquei preso e não consigo mais sair, tentarei novamente na próxima rodada!

CASA 3) Vi ali que estão passeando de canoa, e olha que legal: ela não possui motor! Muito bom, não tem barulho para me estressar, não põe ninguém em risco e ainda enfeita a paisagem. Sem falar que é uma delícia! Vou nadar mais duas casas e apreciar o pôr do sol com eles.

CASA 4) SORTE OU AZAR! PERGUNTA: Qual a importância de descartar o lixo corretamente (na lixeira)?

CASA 5) Permaneça no mesmo lugar!

CASA 6) Você sabia que o Tucunaré se chama Cichla monoculus? Tucunaré é seu nome comum ou vulgar e Cichla monoculus é seu nome científico! Ele possui respiração branquial, como a grande maioria dos peixes e pele coberta por escamas. Tem um grande valor econômico, pois sua carne é muito saborosa!

CASA 7) Poxa... tem muita gente passeando na orla hoje, vi ali que tomaram um refrigerante e colocaram a latinha no lixo. Como estou feliz!!! Nem eu, nem meus amigos ficaremos presos ou comeremos lixo por engano! Nadarei mais duas casas!!

CASA 8) SORTE OU AZAR! PERGUNTA: Qual o tipo de respiração da grande maioria dos peixes ?

CASA 9) Permaneça no mesmo lugar!

CASA 10) Você já ouviu falar da piranha-verdadeira? Pois então vou apresentá-la: Seu nome científico é Pygocentrus piraya, é uma espécie nativa do rio São Francisco, possui corpo em forma de disco, cabeça achatada na frente, boca semiaberta deixando visíveis seus dentes triangulares, laminares e aguçados. Uma dentição poderosa, né?!

CASA 11) $\mathrm{Na}$ agricultura costumam usar muito agrotóxico e com a chuva, acaba chegando aqui. Tenho muito medo de ser contaminado. Voltarei 5 casas!

CASA 12) Uma vez ouvi falar que na escola, as vezes não tem lata de lixo por perto, mas o pessoal guarda o saquinho da pipoca para descartá-lo no local adequado! Esse pessoal sabe mesmo como preservar o meio ambiente! Vou nadar mais 4 casas!

CASA 13) SORTE OU AZAR! PERGUNTA: Como a agricultura polui as águas?

CASA 14) Outra espécie muito conhecida é o curimatã-pacu, com nome científico Prochilodus argenteus, assim como a maioria dos peixes, ele possui nadadeira dorsal, peitoral, pélvica, adiposa, anal e caudal. Show, ne ?!

CASA 15) SORTE OU AZAR! PERGUNTA: Quais as principais causas da poluição da água ?

CASA 16) Permaneça no mesmo lugar!

CASA 17) Quando se fala em saneamento, estamos nos referindo às condições de saúde pública relacionadas à água potável e ao tratamento e despejo correto de esgotos humano.

CASA 18) SORTE OU AZAR! PERGUNTA: Qual a importância do saneamento básico?

CASA 19) Você sabia que os peixes possuem sistema digestório completo? Boca, estômago, intestino e ânus! E sua dentição varia de acordo com o tipo de alimento preferido deles!

CASA 20) Muito bom morar em uma cidade banhada pelo rio, né? Mas vocês ai da cidade insistem em despejar o esgoto aqui. Que nojo, vou me contaminar todo!! Nadarei de volta 3 casas.

CASA 21) Como fertilizante de sua roça de milho o pessoal preferiu utilizar adubo orgânico. Que pessoal esperto! Nadarei 6 casas de tão feliz que fiquei!

CASA 22) SORTE OU AZAR! PERGUNTA: Quais as partes do sistema digestório dos peixes?

CASA 23) O aterro sanitário é o local adequado onde o lixo será depositado e descartado.

CASA 24) SORTE OU AZAR! PERGUNTA: Qual o problema do despejo de esgotos em rios?

CASA 25) O acúmulo de sedimentos como areia, rochas e até mesmo lixo levados até o leito dos cursos d'água pela ação da chuva, do vento ou do ser humano é chamado de assoreamento.

CASA 26) O pessoal costuma utilizar uma balsa enorme para atravessar com seus carros e motos, eu sei que lá tem lixeira, mas viviem jogando embalagem de picolé aqui no rio. Que pessoal imundo! Nadarei 3 casas de volta! 


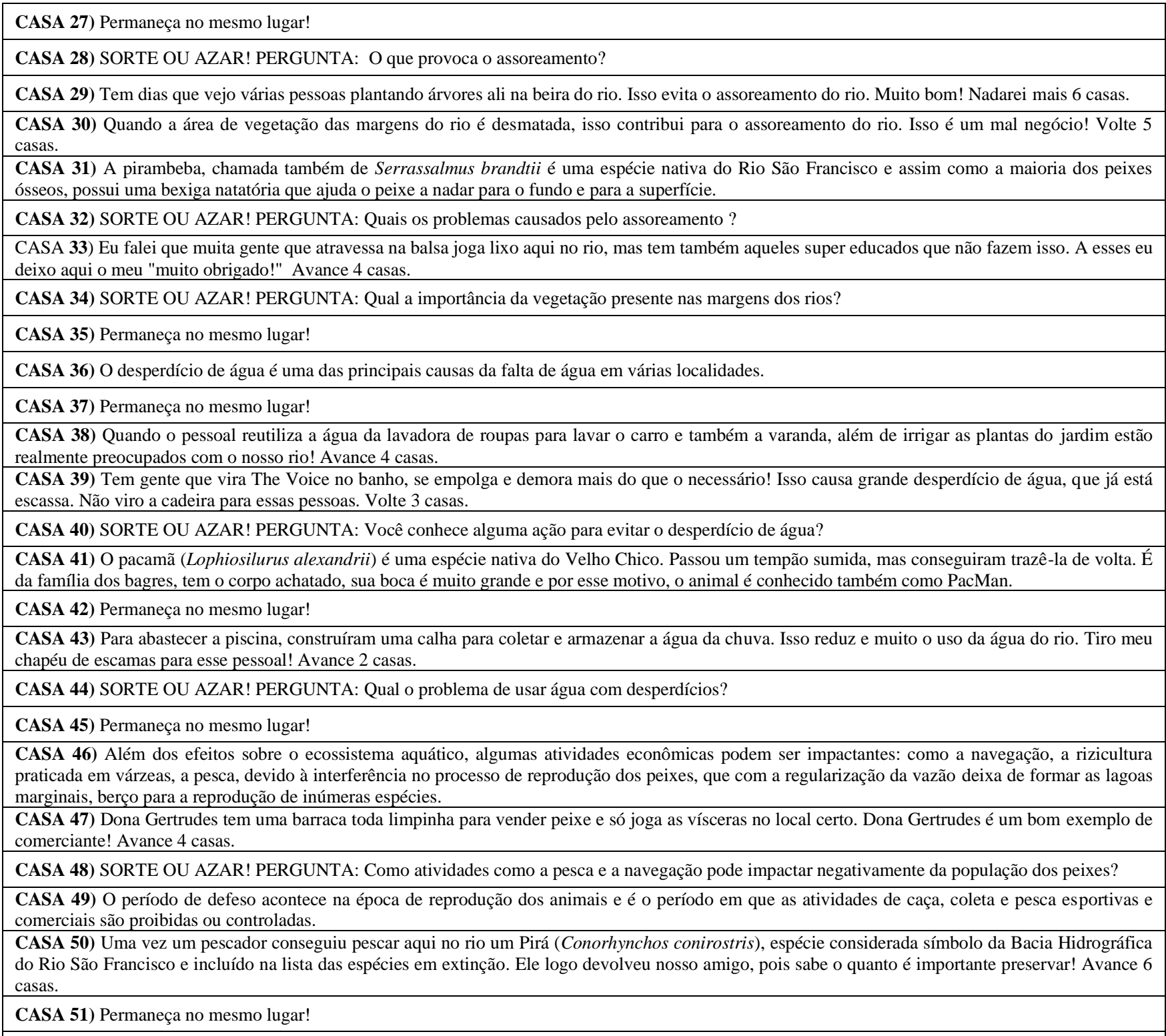

CASA 52) A gente não fica com raiva porque as pessoas pescam, a gente sabe que é algo importante, mas por favor, não pesquem nossos peixes bebês, corremos o risco de sumir! Sejam mais conscientes! Volte 3 casas.

CASA 53) As principais atividades econômicas praticadas são a navegação, a rizicultura (plantação de arroz), a pesca e turismo.

CASA 54) Poluição ambiental é qualquer atividade capaz de causar danos ao meio ambiente.

CASA 55) Você escolheu um lugar para nadar, mas a correnteza está trazendo lixo e esgoto descartados incorretamente logo acima no rio, próximo ao Museu. Não é culpa sua mas terá que voltar 1 casa.

CASA 56) Apesar de gostar muito de pescar no rio, como estava na época de reprodução das espécies, você preferiu apenas nadar e aproveitar o banho. Avance 2 casas.

CASA 57) Por causa da diminuição da vazão, o mar consegue avançar muito e vários peixes marinhos conseguem chegar até aqui. Um exemplo deles é o Bagre do mar (Cathorops agassizii).

CASA 58) Permaneça no mesmo lugar!

CASA 59) O coletor de material reciclável é considerado um importante agente ambiental, pois a partir da reciclagem o impacto ao meio ambiente diminui.

CASA 60) La na prainha, muita gente não recolhe o lixo que leva, e já sabemos o mal que isso nos faz né? Que chato! Voltei 1 casa.

CASA 61) O regime de vazões do rio São Francisco nessa região é regido pelos reservatórios localizados nas partes mais altas da bacia, como as barragens de Sobradinho, Itaparica e Xingó. Como consequência, há uma redução gradual dos fluxos mínimos no rio, com impactos significativos, dentre os quais o avanço do mar na região da foz.

CASA 62) Quase lá! Estamos quase no final e já aprendemos sobre os peixes do velho chico e como praticar a preservação. É uma boa sensação! Nadarei 2 casas!

CASA 63) SORTE OU AZAR! PERGUNTA: Como podemos evitar a poluição dos rios?

CASA 64) CHEGADA - PARABÉNS, aprendemos muito hoje!! 